\title{
LETTER
}

\section{Hospital mortality in mechanically ventilated COVID-19 patients in Mexico}

\author{
Silvio A. Namendys-Silva ${ }^{1,2^{*}}$ (], Alan Gutiérrez-Villaseñor ${ }^{3}$ and Juan P. Romero-González ${ }^{3}$
}

(c) 2020 Springer-Verlag GmbH Germany, part of Springer Nature

\section{Dear Editor,}

As of August $13^{\text {th }}, 2020$, a total of $20,439,814$ confirmed cases of coronavirus disease 2019 (COVID-19) have been reported to the World Health Organization, and 744,385 lives have been lost [1]. The Americas constitute the current epicentre of the COVID-19 pandemic. A total of 505,751 confirmed cases of COVID-19 and 55,293 deaths have been reported in Mexico [2], and 2.5\% of these patients have required endotracheal intubation and invasive mechanical ventilation [2]. This report describes the sociodemographic characteristics and comorbidities associated with mortality in mechanically ventilated adults with COVID-19 in Mexico.

We analysed data collected in the General Epidemiology Directorate of the Mexican Ministry of Heath, which is an open-source dataset comprising of daily updated data of suspected COVID-19 cases that were confirmed by a positive test for SARS-CoV-2 [2]. We used the version released on August $13^{\text {th }}, 2020$ [2].

A total of 12,018 mechanically ventilated adults with COVID-19 were included. The flow chart of the study is shown in Figure S1 (supplemental methods). The median age was 60 years (interquartile range 50-69; range 18-108 years), and 7971 (66.3\%) were men (Figure S2) (supplementary material). The sociodemographic characteristics and comorbidities of the patients with COVID-19 (according to in-hospital deaths) are shown in Table 1. A total of $57.6 \%(n=6928)$ of the patients were mechanically ventilated outside of the intensive care

\footnotetext{
*Correspondence: snamendys@gmail.com

${ }^{1}$ Division of Pulmonary, Anesthesia and Critical Care Medicine, Instituto Nacional de Ciencias Médicas y Nutrición Salvador Zubirán, 14000 Mexico City, Mexico

Full author information is available at the end of the article
}

units (Figure S1) (supplementary material). The overall in-hospital mortality was $73.7 \%(n=8861)$.

In our report, hospital mortality was higher than mortality in high-income countries such as the United Kingdom $(67.4 \%$ versus $73.7 \%, p<0.001)[3]$ and Germany (53\% versus $73.7 \%, p<0.001$ ) [4]. Furthermore, hospitalisation in the public healthcare system presented higher crude mortality compared with the private healthcare system (Figure S3) (supplementary material).

Mexican health authorities have stated that the response to the pandemic has been satisfactory because the health system has not been affected and because sufficient numbers of beds with ventilators are available. As shown in this report, the availability of sufficient numbers of beds with ventilators does not ensure improvement in the prognoses of patients with COVID-19. Beyond the quantity of beds with ventilators, there may also be concerns about the quality of care, as has been suggested by the high mortality rate for intubated COVID-19 patients in Mexico. Health care systems in low- and middleincome countries should be concerned about having sufficient qualified personnel (such as nurses and physicians) and other resources (such as personal protective equipment), which has been one of the main problems worldwide during the COVID-19 pandemic.

The main limitation of this study is the use of a nationwide administrative database that was not designed for clinical research. However, it is useful to present the general overview of mechanically ventilated COVID-19 patients in Mexico. Additionally, we excluded patients

\section{望 Springer}


Table 1 Characteristics of mechanically ventilated COVID-19 patients, according to in-hospital death

\begin{tabular}{|c|c|c|c|c|}
\hline Characteristics & $\begin{array}{l}\text { Total population } \\
(n=12,018)\end{array}$ & $\begin{array}{l}\text { Survivors } \\
(n=3157)\end{array}$ & $\begin{array}{l}\text { Non-survivors } \\
(n=\mathbf{8 8 6 1})\end{array}$ & $p$ value* \\
\hline Age, years, median (interquartile range) & $60(50-69)$ & $56(46-66)$ & $61(51-70)$ & $<0.001$ \\
\hline $18-34$ & $581(4.8)$ & $270(8.5)$ & $311(3.5)$ & $<0.001$ \\
\hline $35-54$ & $3740(31.1)$ & $1188(37.6)$ & $2551(28.7)$ & \\
\hline $55-64$ & $3313(27.6)$ & $823(26.1)$ & $2490(28.1)$ & \\
\hline$\geq 65$ & $4384(36.5)$ & $876(27.7)$ & $3508(39.6)$ & \\
\hline Female, $n(\%)$ & $4047(33.7)$ & $1086(34.4)$ & $2961(33.4)$ & 0.315 \\
\hline Male, $n(\%)$ & $7971(66.3)$ & $2071(65.6)$ & $5900(66.6)$ & \\
\hline Ability to speak a Mexican indigenous language, $n(\%)$ & $221(1.8)$ & $41(1.3)$ & $180(2)$ & 0.009 \\
\hline Medical treatment in the public healthcare system, $n$ (\%) & $11,468(95.4)$ & $2877(91.1)$ & $8591(96.9)$ & $<0.001$ \\
\hline Medical treatment in the private healthcare system, $n(\%)$ & $550(4.6)$ & $280(8.8)$ & $270(3)$ & \\
\hline Time from illness onset to hospital admission > 6 days, $n$ (\%) & $3693(30.7)$ & $1063(33.7)$ & $2630(29.7)$ & $<0.001$ \\
\hline Invasive mechanical ventilation outside intensive care unit, $n(\%)$ & $6928(57.7)$ & $1714(54.3)$ & $5214(58.8)$ & $<0.001$ \\
\hline Invasive mechanical ventilation in the intensive care unit, n (\%) & $5090(42.3)$ & $1443(45.7)$ & $3647(41.1)$ & \\
\hline \multicolumn{5}{|l|}{ Comorbidities, $n(\%)$} \\
\hline Hypertension & $4802(40)$ & $1109(35.1)$ & $3693(41.7)$ & $<0.001$ \\
\hline Diabetes & $4349(36.2)$ & $1019(32.3)$ & $3330(37.6)$ & $<0.001$ \\
\hline Obesity & $3388(28.2)$ & $895(28.3)$ & $2493(28.1)$ & 0.818 \\
\hline Chronic kidney disease & $603(5)$ & $137(4.4)$ & $466(5.3)$ & 0.042 \\
\hline Cardiovascular disease & $590(4.9)$ & $141(4.5)$ & $449(5)$ & 0.180 \\
\hline Chronic obstructive lung disease & $463(3.9)$ & $85(2.6)$ & $378(4.3)$ & $<0.001$ \\
\hline Immunosuppression & $281(2.3)$ & $62(2)$ & $219(2.5)$ & 0.105 \\
\hline Asthma & $237(2)$ & $55(1.7)$ & $182(2)$ & 0.279 \\
\hline No comorbidities** & $3712(30.9)$ & $1116(35.3)$ & $2596(29.3)$ & $<0.001$ \\
\hline$\geq 1$ comorbidity & $8306(69.1)$ & $2041(64.6)$ & $6265(70.7)$ & \\
\hline
\end{tabular}

${ }^{*}$ Chi-square (categorical variables) or Mann-Whitney (continuous variables) tests ( $a=0.05$ )

**No comorbidities: patients had none of the listed comorbidities

who died outside of hospitals or who died before intubation.

\section{Electronic supplementary material}

The online version of this article (https://doi.org/10.1007/s00134-020-06256-3) contains supplementary material, which is available to authorized users.

\section{Author details}

${ }^{1}$ Division of Pulmonary, Anesthesia and Critical Care Medicine, Instituto Nacional de Ciencias Médicas y Nutrición Salvador Zubirán, 14000 Mexico City, Mexico. ${ }^{2}$ Department of Critical Care Medicine, Instituto Nacional de Cancerología, Mexico City, Mexico. ${ }^{3}$ Department of Critical Care Medicine, Hospital Médica Sur, Mexico City, Mexico.

\section{Acknowledgements}

This report is dedicated to all patients and health care workers who died due to COVID-19 in Mexico and around the world.

\section{Author contributions}

ÑS had full access to all of the data in the report and take responsibility for the integrity of the data and the accuracy of the data analysis. Concept and design: ÑS. Acquisition, analysis, or interpretation of data: All authors. Drafting of the manuscript: NS. Critical revision of the manuscript for important intellectual content: All authors. Statistical analysis: ÑS. Administrative, technical, or material support: ÑS. Supervision: ÑS.

\section{Compliance with ethical standards}

\section{Conflicts of interest}

The authors declared no conflict of interest.

\section{Publisher's Note}

Springer Nature remains neutral with regard to jurisdictional claims in published maps and institutional affiliations.

Accepted: 19 September 2020

Published online: 30 September 2020

\section{References}

1. World Health Organization (2020) Coronavirus disease 2019 (COVID-19): situation report, 206. https://www.who.int/docs/default-source/coron aviruse/situation-reports/20200813-covid-19-sitrep-206.pdf?sfvrsn=bf38f 66b 6. Accessed 15 Sept 2020

2. Datos Abiertos - Dirección General de Epidemiología, Secretaría de Salud Gobierno de México. http://datosabiertos.salud.gob.mx/gobmx/salud 
/datos_abiertos/historicos/08/datos_abiertos_covid19_13.08.2020.zip. Accessed 15 Sept 2020

3. ICNARC report on COVID-19 in critical care, 17 April 2020. https:// www.icnarc.org/DataServices/Attachments/Download/c5a62b136486-ea11-9125-00505601089b. Accessed 15 Sept 2020

4. Karagiannidis C, Mostert C, Hentschker C, Voshaar T, Malzahn J, Schillinger G, Klauber J, Janssens U, Marx G, Weber-Carstens S, Kluge S, Pfeifer M,
Grabenhenrich L, Welte T, Busse R (2020) Case characteristics, resource use, and outcomes of 10021 patients with COVID-19 admitted to 920 German hospitals: an observational study. Lancet Respir Med 8(9):853862. https://doi.org/10.1016/S2213-2600(20)30316-7 